\title{
Aggregation of cation-anionic and related polymethine dyes
}

\author{
A. S. Tatikolov, ${ }^{1}$ G. Ponterini, ${ }^{2}$ and Zh. A. Krasnaya ${ }^{3}$ \\ ${ }^{1}$ Institute of Biochemical Physics, Russian Academy of Sciences, Kosygin Str. 4, 117977 Moscow, Russia \\ ${ }^{2}$ Dipartimento di Chimica, Universita di Modena, via Campi 183, 41110 Modena, Italy \\ ${ }^{3}$ Institute of Organic Chemistry, Russian Academy of Sciences, Leninsky Pr. 47, 117913 Moscow, Russia
}

\begin{abstract}
Absorption, fluorescence, and fluorescence excitation spectra were studied for a number of cation-anionic and related anionic polymethine dyes in weakly polar and nonpolar solvents, as well as in binary mixtures of solvents of different polarity. For some dyes, aggregation is observed in toluene or acetonitrile-toluene mixtures with low amounts of acetonitrile, which is revealed as appearance of new absorption bands and/or broadening of the initial bands of a monomeric dye. Solvent mixtures butyronitrilehexane with low butyronitrile content were found to greatly stimulate the formation of dye aggregates for most of the dyes studied. The absorption spectra of the aggregates are often blue-shifted with respect to the corresponding absorption spectra of parent monomeric dyes and/or represent broad continuums located both in the blue and red regions. For one of the cation-anionic dyes studied, which consists of 3,3'-diethylthiamonomethinecyanine cation and trimethinebenzoxanine anion, fluorescent aggregates were observed; their broad fluorescence band is located in the long-wavelength region. For this dye, gradual transition from nonfluorescent aggregates to fluorescent ones and then to monomeric ion pairs and dissociated ions was observed in butyronitrile-hexane mixtures with growing butyronitrile content.
\end{abstract}

\section{INTRODUCTION}

The ability of polymethine dyes to form associates (aggregates) is widely used in spectral sensitization of photographic materials [1]. The analysis of the conditions under which both fluorescent and nonfluorescent aggregates are formed is of considerable scientific and practical interest also due to the use of high concentrations of polymethine dyes in dye lasers [2] and emission converters [3]. The processes of molecular association of polymethine dyes were mainly studied in water [4] (in some cases, in organic solvents [5]). In spite of a great deal of investigation, many problems concerning the processes of molecular association of polymethine dyes and the properties of the aggregates remain to be unsolved due to their complexity and diversity. Detailed reviews devoted to the association of dye molecules have been presented elsewhere (see, e.g., [4, 6, 7]).

Until recently, the association of identical molecules of dyes (formation of homogeneous aggregates) was usually investigated. However, aggregates may also be formed from different dye molecules (heterogeneous aggregates), which results in a difference between the electronic spectrum of the mixture of two dyes and the sum of the spectra of its components [8, 9]. Recently we studied the spectral and fluorescence properties of the heterogeneous aggregates formed by some cationanionic polymethine dyes, whose molecules consist of cation and anion dyes $[10,11]$. In the present work, aggregates of some new cation-anionic polymethine dyes as well as of related simple anionic polymethine dyes were found and investigated in weakly polar and nonpolar solvent media.

\section{EXPERIMENTAL}

The polymethine dyes studied contained the following dye anions:<smiles>[R]C(=CC1=C(O)c2ccccc2C1=O)C1C(=O)c2ccccc2C1=O</smiles>

where $\mathrm{R}=\mathrm{H}\left(\mathrm{A}_{1}\right), \mathrm{F}\left(\mathrm{A}_{2}\right)$;<smiles>CCCCCCCC=CC1=C(O)c2ccccc2C1=O</smiles><smiles>O=C1C(C=CC=c2c(=O)c3cccc4cccc(c2=O)c43)=C(O)c2cccc3cccc1c23</smiles>

$\left(\mathbf{A}_{4}\right)$,<smiles>COC1=C(/C=C/C=C2C(=O)CCCC2=O)C(=O)CCC1</smiles>

(A),<smiles>CC1(C)CC(=O)C(=CC=CC2=C(O)CC(C)(C)CC2=O)C(=O)C1</smiles>

(A), 
<smiles>COC1=C(C=C(C)C=C2C(=O)OC(C)(C)OC2=O)C(=O)OC(C)(C)O1</smiles>

and the cations:<smiles>[R]/C(C=[N+](C)C)=C/N(C)C</smiles>

where $\mathrm{R}=\mathrm{H}\left(\mathrm{C}_{1}\right), \mathrm{F}\left(\mathrm{C}_{2}\right), \mathrm{Me}\left(\mathrm{C}_{3}\right)$,<smiles>CC[n+]1c(C=C2Nc3ccccc3S2)sc2ccccc21</smiles>

$\left(\mathrm{C}_{4}\right)$,<smiles>[R]C(/C=C/C1=[N+]c2ccccc2S1)=C\C=C1/Nc2ccccc2S1</smiles>

where $\mathrm{R}=\mathrm{H}\left(\mathrm{C}_{5}\right), \quad \mathrm{Me}\left(\mathrm{C}_{6}\right)$, as well as $\mathrm{K}^{+}\left(\mathrm{C}_{7}\right)$, $\mathrm{Me}_{2} \mathrm{NH}_{2}^{+}\left(\mathrm{C}_{8}\right)$, and $\mathrm{Et}_{3} \mathrm{NH}^{+}\left(\mathrm{C}_{9}\right)$.

Butyronitrile, toluene, butyronitrile-hexane and acetonitrile-toluene mixtures with different butyronitrile or acetonitrile contents were used as solvents. Toluene was refluxed over metal sodium and stored over molecular sieves. Because of very low solubility of the dyes in toluene, the solutions in toluene were prepared by fine grinding of small amounts of dyes wet with toluene. Absorption spectra were recorded on a Perkin-Elmer $\lambda 15$ spectrophotometer using cells with $1 \mathrm{~cm}$ path length. Fluorescence spectra were recorded using a FluoroMax-2 Jobin-Yvon-Spex spectrofluorimeter (the spectra were not corrected for spectral sensitivity of the spectrofluorimeter). Concentrations of the dyes were in the range of $10^{6}-10^{5} \mathrm{M}$. All measurements were performed at $20 \pm 2^{\circ} \mathrm{C}$.

\section{RESULTS AND DISCUSSION}

Table 1 presents the absorption and fluorescence maxima for the dyes studied in butyronitrile, toluene, butyronitrile-hexane and acetonitrile-toluene mixtures.

In polar solvents (e.g., acetonitrile, butyronitrile) the absorption and fluorescence spectra of the dyes under investigation correspond to those of dissociated ions: the spectra contain one band for anionic dyes (with simple cations $\mathrm{K}^{+}, \mathrm{Me}_{2} \mathrm{NH}_{2}^{+}, \mathrm{Et}_{3} \mathrm{NH}^{+}$) and two bands in the case of cation-anionic dyes (cations $\mathrm{C}_{1}$, $\mathrm{C}_{2}$, and $\mathrm{C}_{3}$ have the absorption bands in the UV region with $\lambda_{\text {abs }}{ }^{\max }=310-320 \mathrm{~nm}$ not shown in Table1 and figures). In weakly polar and nonpolar solvents (toluene; butyronitrile-hexane mixtures with low butyronitrile contents), additional bands sometimes appear in the absorption spectra of the dyes (see Table 1). Absorption bands due to aggregate formation can appear both in the short-wavelength and long-wavelength regions with respect to the initial bands $[10,11]$. As to fluorescence of the aggregates, it appears only in the longwavelength region [10,11]. The aggregates observed in the absorption spectra often exhibit a broad absorption without any characteristic maxima (a broad continuum) due to their disordered structure. Relative intensities of these bands increase with growing dye concentration and, in mixtures of solvents differing in polarity, with growing content of a nonpolar component. To test the reversibility of the aggregate formation, addition of butyronitirile or acetonitrile to the dye solutions containing aggregates was used, which led to disappearance of aggregate bands.

In toluene, aggregation of dyes $\mathbf{2}$ and $\mathbf{3}$ is revealed as broadening of the initial absorption spectra of monomers and appearance of additional blue-shifted aggregate bands (see Table 1; dye 3 was studied in acetonitrile-toluene mixtures because it is not dissolved in neat toluene). In the case of dyes 5,7 , and $\mathbf{8}$, only broadening of the spectra is observed. Other dyes reveal no appreciable features of aggregation. No fluorescent aggregates were found in toluene.

Figure 1 shows as an example the absorption spectra of the anionic dye 3 in acetonitrile-toluene mixtures. In the mixture containing relatively low amount of acetonitrile (4.8 vol\%), an intense band of aggregates is observed in the absorption spectrum $\left(\lambda_{\mathrm{abs}}{ }^{\max }=390 \mathrm{~nm}\right)$,

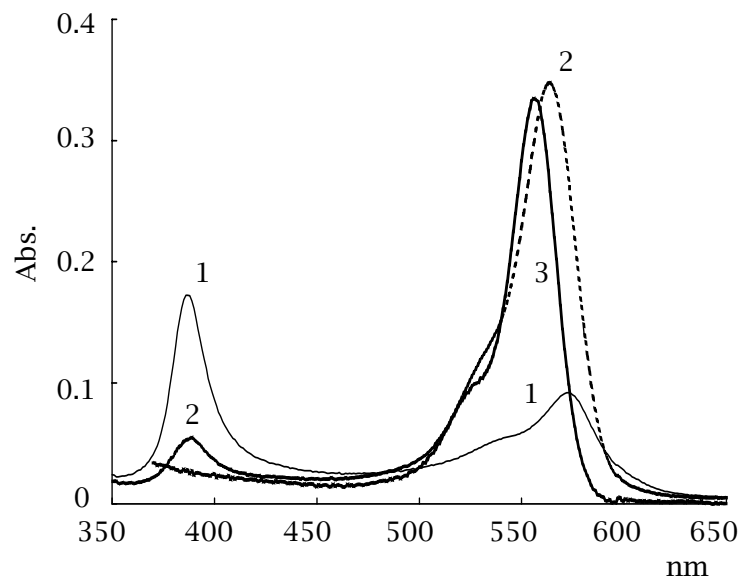

Figure 1. Absorption spectra of dye 3 in acetonitriletoluene mixtures containing 4.8 (1) and $24 \mathrm{vol \%}$ (2) of acetonitrile, as well as in neat butyronitrile (3). Concentration of the dye was $\sim 10^{-6} \mathrm{M}$. 
Table 1. Absorption $\left(\lambda_{\mathrm{abs}}{ }^{\max }\right)$ and fluorescence $\left(\lambda_{\mathrm{fl}}{ }^{\max }\right)$ maxima for dyes 1-12 in butyronitrile, toluene, and butyronitrilehexane mixtures. (Note: sh, shoulder. ${ }^{*}$ Maxima of bands corresponding to aggregates.)

\begin{tabular}{|c|c|c|c|c|c|c|c|c|}
\hline \multirow[b]{2}{*}{ Dye } & \multirow[b]{2}{*}{ Anion } & \multirow{2}{*}{ Cation } & \multicolumn{2}{|c|}{$\mathrm{BuCN}$} & \multicolumn{2}{|c|}{ Toluene } & \multirow{2}{*}{\begin{tabular}{|l} 
BuCN - hexane \\
$\lambda_{\text {abs }}{ }^{\max }, \mathrm{nm}$
\end{tabular}} & \multirow{2}{*}{$\begin{array}{l}\text { BuCN-hexane } \\
\lambda_{\mathrm{fl}}{ }^{\max }, \mathrm{nm}\end{array}$} \\
\hline & & & $\lambda_{\mathrm{abs}}{ }^{\max }, \mathrm{nm}$ & $\lambda_{\mathrm{fl}}^{\max }, \mathrm{nm}$ & $\lambda_{\mathrm{abs}}^{\max }, \mathrm{nm}$ & $\lambda_{\mathrm{fl}}^{\max }, \mathrm{nm}$ & & \\
\hline 1 & $\mathbf{A}_{1}$ & $\mathrm{C}_{1}$ & 556 & 571 & 574 & 595 & 563(0.45 vol.\%) & 580 \\
\hline 2 & $\mathbf{A}_{1}$ & $\mathrm{C}_{4}$ & $423 ; 556$ & $465 ; 571$ & $\begin{array}{c}407^{*} ; 426 ; \\
577 \\
\end{array}$ & $\sim 463 ; \sim 584$ & $\begin{array}{l}404^{*} ; 425 \mathrm{sh} ; \\
573 \text { (0.5 vol\%) }\end{array}$ & no fluorescence \\
\hline 3 & $\mathbf{A}_{1}$ & $\mathrm{C}_{7}$ & 556 & 571 & $\begin{array}{l}\text { 390*; } 573 \\
\text { (MeCN-tolı }\end{array}$ & $\begin{array}{c}595 \\
\text { luent } 1: 20)\end{array}$ & $\begin{array}{l}386^{*} ; ~ 520-580^{*} \\
\text { (broad) (1.1 vol\%) }\end{array}$ & $\begin{array}{l}\sim 580 \\
\text { (very weak) }\end{array}$ \\
\hline 4 & $\mathbf{A}_{2}$ & $\mathrm{C}_{2}$ & 571 & 583 & 588 & 598 & $\begin{array}{l}\sim 390-550^{*} \text { (broad); } \\
580 \mathrm{sh}(0.4 \text { vol\%) }\end{array}$ & no fluorescence \\
\hline 5 & $\mathbf{A}_{2}$ & $\mathrm{C}_{6}$ & $571 ; 651$ & $583 ; 667$ & $573 ; 666$ & $598 ; 672$ & $\begin{array}{l}\text { broad } \sim 500-700^{*} ; \\
(0.6 \text { vol\%) }\end{array}$ & no fluorescence \\
\hline 6 & $\mathbf{A}_{2}$ & $\mathrm{C}_{8}$ & 571 & 583 & 588 & $\sim 600$ & $\begin{array}{l}413^{*} \text { (broad); } \\
583 \text { (1.1 vol\%) }\end{array}$ & $\begin{array}{l}\sim 592 \\
\text { (very weak) }\end{array}$ \\
\hline 7 & $\mathbf{A}_{3}$ & $\mathrm{C}_{9}$ & 659 & 678 & 665 & 692 & & \\
\hline 8 & $\mathbf{A}_{4}$ & $\mathrm{C}_{1}$ & 565 & 581 & 574 & 595 & $\begin{array}{l}402 * ; 575 ; \\
546 \operatorname{sh}^{*}(9 \text { vol\%) } \\
\end{array}$ & 585 \\
\hline 9 & $\mathbf{A}_{5}$ & $\mathrm{C}_{1}$ & 507 & 534 & 513 & 542 & $\begin{array}{l}510, \sim 545 \\
555 \operatorname{sh}^{*}(3.3 \text { vol\%) }\end{array}$ & 539 \\
\hline 10 & $\mathbf{A}_{6}$ & $\mathrm{C}_{1}$ & 505 & 533 & 511 & 540 & $\begin{array}{l}509 ; \sim 555 \mathrm{sh}^{*} \\
(0.46 \text { vol\%) }\end{array}$ & very weak \\
\hline 11 & $A_{7}$ & $\mathrm{C}_{3}$ & $315 ; 468$ & $\begin{array}{l}\sim 510 \\
\text { (weak) }\end{array}$ & $323 ; 474$ & very weak & $\begin{array}{l}322 ; 470 \\
(0.5 \text { vol\%) }\end{array}$ & very weak \\
\hline 12 & $A_{7}$ & $\mathrm{C}_{3}$ & $468 ; 654$ & $\begin{array}{c}\sim 510 \\
\text { (weak); } 673\end{array}$ & $470 ; 679$ & $\begin{array}{c}\sim 510 \\
\text { (weak); } 697\end{array}$ & $\begin{array}{l}470 ; 557 \mathrm{sh}^{*} ; \\
670 \text { (0.5 vol\%) }\end{array}$ & 690 \\
\hline
\end{tabular}

along with the band of the monomeric dye $\left(\lambda_{\mathrm{abs}} \max _{=}\right.$ $573 \mathrm{~nm}$; curve 1 in Figure 1). With increasing acetonitrile content, the intensity of the band of dye aggregates decreases with a simultaneous increase in the intensity of the band of the monomeric dye $\left(\lambda_{\mathrm{abs}}{ }^{\max }=562 \mathrm{~nm}\right.$; curve 2 in Figure 1). In a neat polar solvent, butyronitrile, only the band of the dissociated monomeric dye (dye anion) is present in the spectrum $\left(\lambda_{\mathrm{abs}}{ }^{\max }=556 \mathrm{~nm}\right.$; curve 3 in Figure 1).

We have found that a majority of the dyes studied (except for 1 and 11) have tendency to strong aggregation in butyronitrile-hexane mixtures containing small amounts of butyronitrile. In these experiments, addition of much hexane to a small amount of a concentrated butyronitrile solution of the dye was found to greatly stimulate formation of dye aggregates. The aggregation is revealed in the absorption spectra as either disappearance of the monomeric bands and appearance of a very broad continuum due to aggregation, which probably indicates formation of very disordered aggregates (as for dyes 4, 5), or appearance of a narrower aggregate band (usually blue-shifted) and broadening of the initial monomeric bands (as for dyes 3, 8). Upon addition of increasing amounts of butyronitirile to aggregate solutions, we can observe a gradual decrease in intensity of the aggregate bands and growing intensity of the monomeric bands, which reflects the shift of the aggregation equilibrium toward dissociation of aggregates with formation of monomers. This is illustrated by Figure 2, which shows the absorption spectra of the cation-anionic dye 5 in butyronitrile-hexane mixtures. A very broad continual band in the region $450-750 \mathrm{~nm}\left(\lambda_{\mathrm{abs}} \max \approx 540 \mathrm{~nm}\right)$ is observed in the mixture with low butyronitrile content (1.8 vol\%). Upon addition of butyronitrile, the continual band vanishes, and the bands of the monomeric

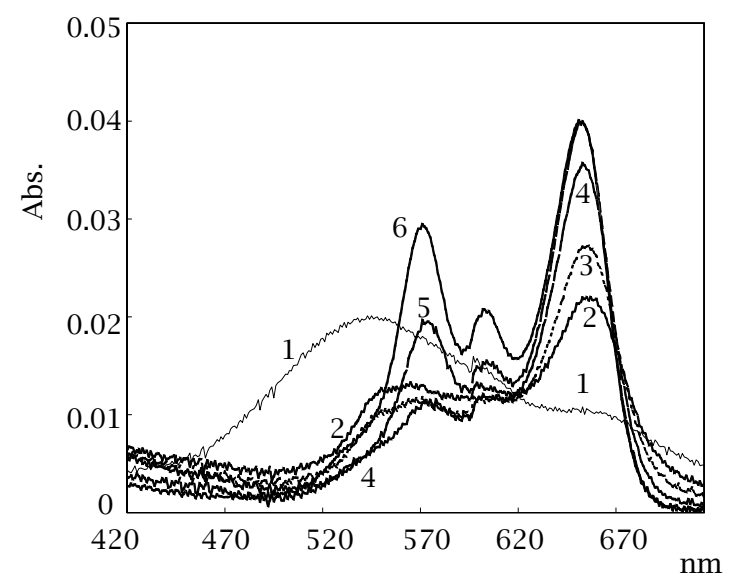

Figure 2. Absorption spectra of dye 5 in butyronitrilehexane mixtures containing 1.8 (1), 7.2 (2), 9.8 (3), 14 (4), and $29 \mathrm{vol \%}$ (5) of butyronitirile, as well as in neat buty- 
ronitrile (6). Concentration of the dye was $\sim 10^{-6} \mathrm{M}$.

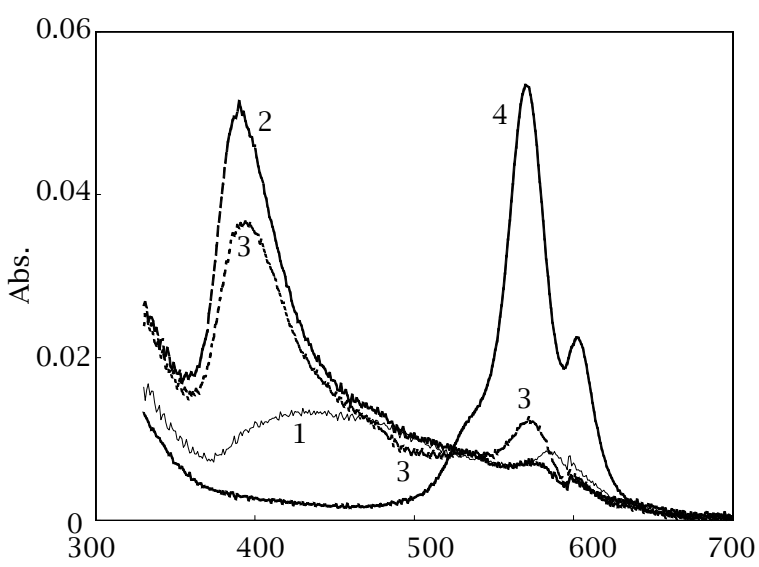

Figure 3. Absorption spectra of dye 4 in butyronitrilehexane mixtures containing 0.4 (1), 9.1 (2), and 17 vol\% (3) of butyronitrile, as well as in neat butyronitrile (4). Concentration of the dye was $\sim 10^{-6} \mathrm{M}$.

dye $\left(\lambda_{\mathrm{abs}}{ }^{\max } \approx 650\right.$ and $570 \mathrm{~nm}$ corresponding to the cation and the anion, respectively) grow in intensity.

The behavior of the cation-anionic dye 4 in butyronitrile-hexane mixtures is more complicated (see Figure 3). The absorption spectrum of dye 4 in the mixtures with small portions of butyronitrile is characterized by a broad continuum in the region 370$630 \mathrm{~nm}$ (curve 1 in Figure 3). Upon addition of moderate butyronitrile amounts (8-20 vol\%), the disordered aggregates having a continual absorption spectrum are rearranged into more ordered ones with a relatively narrow absorption band $\left(\lambda_{\mathrm{abs}}{ }^{\max } \approx 390 \mathrm{~nm}\right.$; curves 2 and 3 in Figure 3). Addition of higher amounts of butyronitrile causes disappearance of the aggregate band with $\lambda_{\mathrm{abs}}{ }^{\max } \approx 390 \mathrm{~nm}$ and growing the band of the monomeric dye (dye anion) with $\lambda_{\text {abs }}{ }^{\max } \approx 570 \mathrm{~nm}$ (curve 4 in Figure 3).

The cation-anionic dye 2 in butyronitrile-hexane mixtures with low butyronitrile contents $(<1.6$ vol\%) exhibits broad low-intense absorption spectra with two maxima: $\lambda_{\text {abs }}{ }^{\max } \approx 420 \mathrm{~nm}$ and $\lambda_{\text {abs }}{ }^{\max } \approx 580 \mathrm{~nm}$, which are assigned to aggregates (Figure $4 \mathrm{a}$ ). An increase in butyronitrile portion leads to growing intensities of these bands and narrowing their shapes due to dissociation of the aggregates and formation of dye ion pairs and free ions (for the long-wavelength band, some blue shift is observed, see Figure 4a). No distinct isosbestic points were observed.

As to the fluorescent properties of dye 2 in butyronitrile-hexane mixtures, it forms nonfluorescent aggregates at butyronitrile contents below 3 vol\%. Weak fluorescence of aggregates with a broad spectrum appears at $[\mathrm{BuCN}]=3.7 \mathrm{vol} \%$ (Figure $4 \mathrm{~b}$, curves $1^{\prime}$ and $2^{\prime}$ ). With increasing butyronitrile content up to $5.9 \mathrm{vol} \%$, the fluorescence intensity rises, and the broad fluorescence spectrum begins to depend on the excitation wavelength, showing the presence of fluorescent aggregates with various structures (apart from the nonfluorescent ones), which emit in the long-wavelength region (Figure $4 \mathrm{~b}$, curves $3^{\prime}$ and $4^{\prime}$ ). At the butyronitrile content $15.6 \mathrm{vol} \%$, a further rise of fluorescence intensity and strong dependence of the fluorescence spectrum on the excitation wavelength is observed. Therewith, upon excitation at the short-wavelength region $(410 \mathrm{~nm})$, a broad emission spectrum of the aggregates is observed (Figure $4 \mathrm{~b}$, curve $5^{\prime}$ ), whereas long-wavelength excitation $(550 \mathrm{~nm})$ causes the fluorescence with a rather narrow spectrum and small Stokes shift (Figure $4 \mathrm{~b}$, curve $6^{\prime}$ ) similar to that of the free dye anion (Figure $4 \mathrm{~b}$, curve $7^{\prime}$ ). This indicates
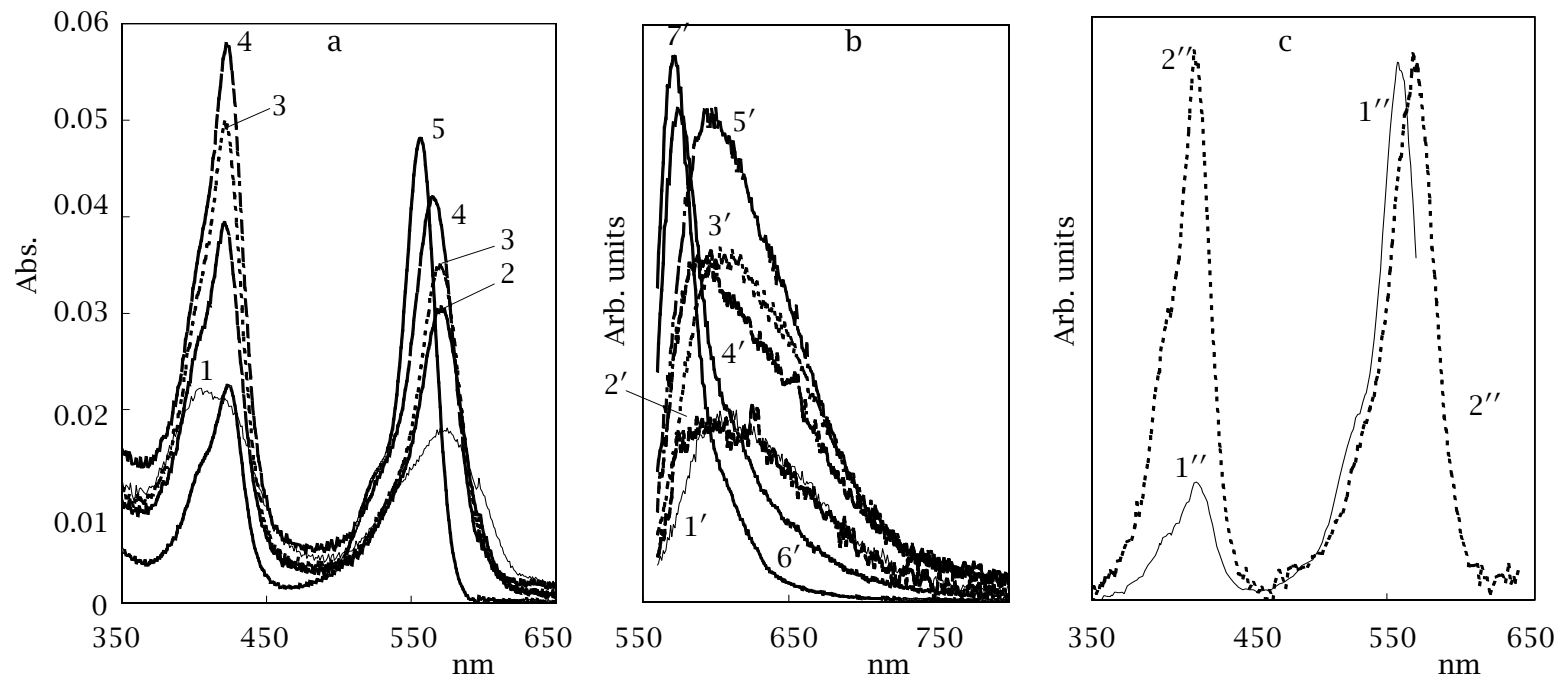

Figure 4. Absorption (a), normalized fluorescence (b) and fluorescence excitation (c) spectra of dye 2 in butyronitrilehexane mixtures containing <1.6 (1), $3.7\left(2,1^{\prime}, 2^{\prime}\right), 5.9\left(3,3^{\prime}, 4^{\prime}\right)$, and $15.6 \mathrm{vol} \%\left(4,5^{\prime}, 6^{\prime}, 1^{\prime \prime}, 2^{\prime \prime}\right)$ of butyronitrile, as well as in neat butyronitrile $\left(7^{\prime}\right) \lambda_{\mathrm{ex}}=410\left(1^{\prime}, 3^{\prime}\right), 420\left(5^{\prime}\right), 520\left(4^{\prime}\right), 530\left(2^{\prime}, 7^{\prime}\right)$, and $550 \mathrm{~nm}\left(6^{\prime}\right) ; \lambda_{\mathrm{em}}=275\left(1^{\prime \prime}\right)$ and 650 
$n m\left(2^{\prime \prime}\right)$. Concentration of the dye $\sim 10^{-6} \mathrm{M}$.

the increasing amounts of free ions (or ion pairs) and fluorescent aggregates (with long-wavelength fluorescence) with rising content of the polar component in the solvent mixture. The fluorescence excitation spectra of dye 2 at $[\mathrm{BuCN}]=15.6 \mathrm{vol}$ (Figure $4 \mathrm{c}$ ) have two bands: short-wavelength $\left(\lambda_{\mathrm{ex}}^{\max }=420 \mathrm{~nm}\right)$ and longwavelength $\left(\lambda_{\mathrm{ex}}{ }^{\max }=560-570 \mathrm{~nm}\right)$; the spectrum with the intense short-wavelength band appears upon the fluorescence monitoring in the region of aggregate emission $\left(\lambda_{\mathrm{em}}=650 \mathrm{~nm}\right)$. It indicates that the fluorescent aggregates mainly absorb in the short-wavelength region and have the absorption spectrum that roughly coincides with that of the free dye cation $\left(\lambda_{\mathrm{ex}}{ }^{\max } \approx\right.$ $425 \mathrm{~nm}$ ). Nevertheless, some long-wavelength absorption of the fluorescent aggregates is also present, which appears as a small bathochromic shift of the longwavelength excitation band upon increasing monitoring wavelength (from $\lambda_{\mathrm{ex}}{ }^{\max }=560 \mathrm{~nm}$ at $\lambda_{\mathrm{em}}=575 \mathrm{~nm}$ to $\lambda_{\mathrm{ex}}{ }^{\max }=570 \mathrm{~nm}$ at $\lambda_{\mathrm{em}}=650 \mathrm{~nm}$ ). Addition of higher amounts of butyronitrile causes dissociation of the aggregates into ion pairs and free ions $\left(\lambda_{\mathrm{abs}}{ }^{\max }=\right.$ 423 and $556 \mathrm{~nm}$ for the cation and the anion, respectively).

Thus, gradual transition from nonfluorescent aggregates to fluorescent ones and then to ion pairs and dissociated ions is observed for dye 2 in butyronitrilehexane mixtures with growing butyronitrile content. The fluorescent aggregates of this dye have the absorption spectrum with two bands (with $\lambda_{\text {abs }}{ }^{\max }=420$ and $\sim 570 \mathrm{~nm}$ ), the short-wavelength band probably being more intense than the long-wavelength one.

\section{ACKNOWLEDGMENTS}

This work was supported by the Russian Foundation for Basic Research (99-03-32116; 97-03-32168a).

\section{REFERENCES}

[1] T. H. James, The Theory of the Photographic Process, 4th Ed., N.-Y., London, 1977.

[2] B. M. Uzhinov, V. I. Yuzhakov, and T. A. Dolenko, Kvantovaya elektronika (Russ. Quantum Electronics) 19 (1992), 7.

[3] A. V. Grachev, A. A. Ishchenko, E. I. Kareeva, V. V. Korotkov, L. V. Levshin, A. F. Oborotov, A. M. Saletsky, and V. I. Yuzhakov, Zhurn. prikl. spektrosk. (Russ. J. Appl. Spectroscopy) 52 (1990), 644.

[4] V. I. Yuzhakov, Uspekhi khimii (Russ. Chem. Rev.) 61 (1992), 1114.

[5] N. Nizamov, T. Sh. Khidirova, U. Zakhidov, and R. Ergashev, Izv. AN SSSR. Ser. fiz. (Russ. Bull. Acad. Sci. USSR. Div. Phys. Sci.) 54 (1990), 502.

[6] A. A. Ishchenko, Uspekhi khimii (Russ. Chem. Rev.) 60 (1991), 1708.

[7] T. Kobayashi, J-Aggregates, World Scientific, Singapore, 1966.

[8] N. Nizamov, T. Sh. Khidirova, and M. O. Yunusova, Zhurn. prikl. spektrosk. (Russ. J. Appl. Spectroscopy) 55 (1991), 881.

[9] R. Kh. Dzhumadinov, A. N. Nizamov, K. U. Umarov, and N. Nizamov, Zhurn. prikl. spektrosk. (Russ. J. Appl. Spectroscopy) 48 (1988), 156.

[10] A. S. Tatikolov, Kh. S. Dzhulibekov, and Zh. A. Krasnaya, Izv. AN SSSR. Ser. khim. (1993), 69 (Translated under the title Russ. Chem. Bull. 42 (1993), $60)$.

[11] A. S. Tatikolov, Kh. S. Dzhulibekov, and Zh. A. Krasnaya, Izv. AN SSSR. Ser. khim. (1995), 476 (Translated under the title Russ. Chem. Bull. 44 (1995), 460). 


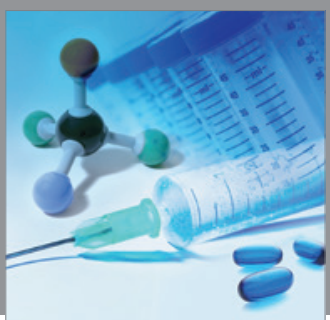

International Journal of

Medicinal Chemistry

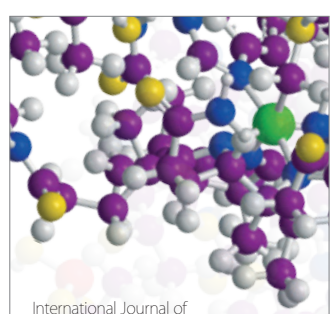

Carbohydrate Chemistry

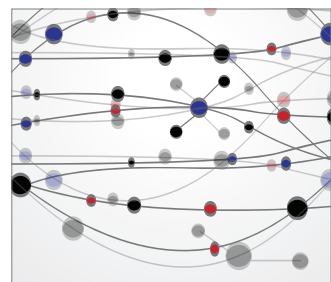

The Scientific World Journal
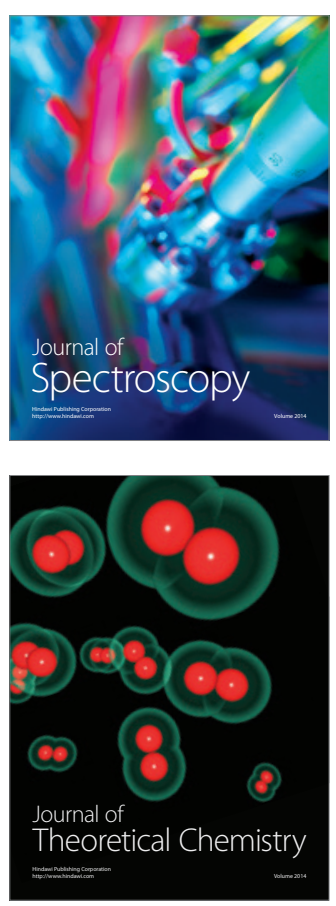
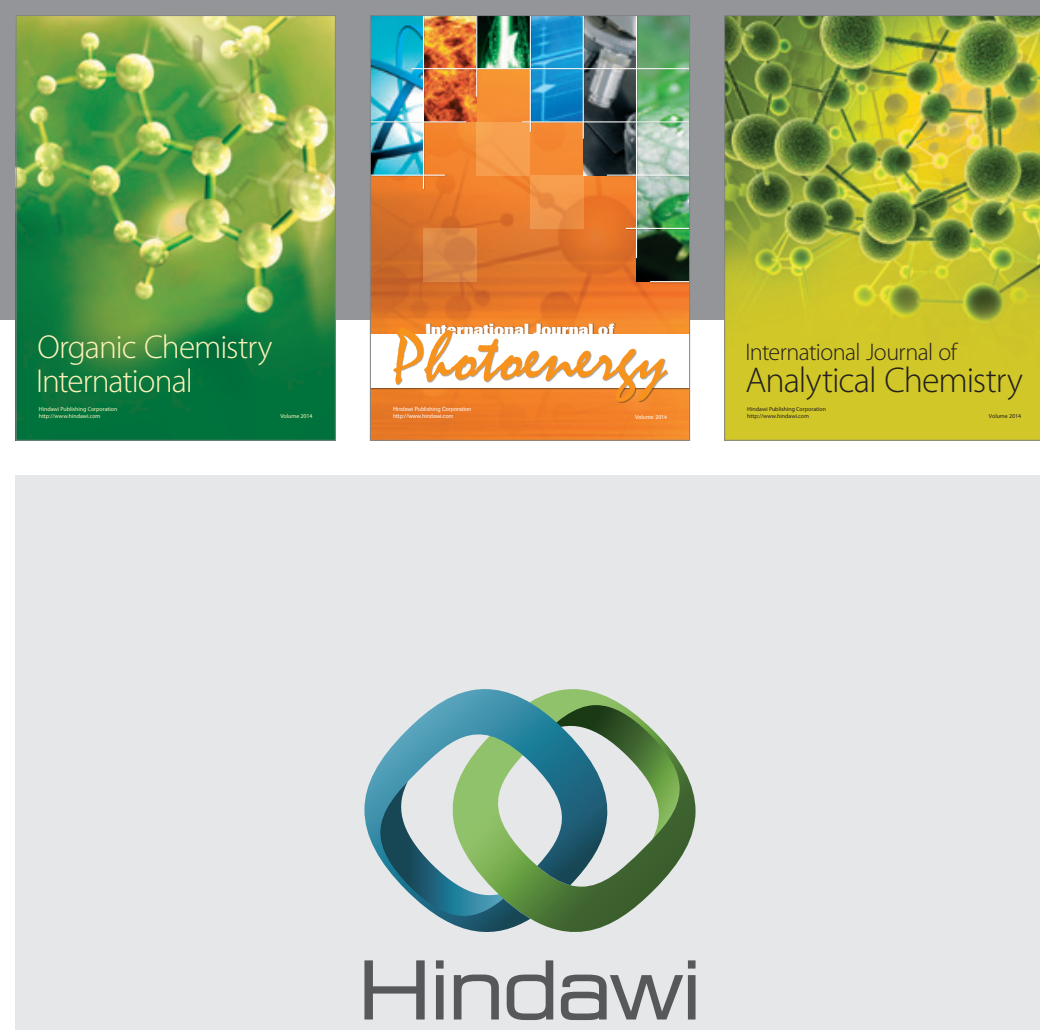

Submit your manuscripts at

http://www.hindawi.com
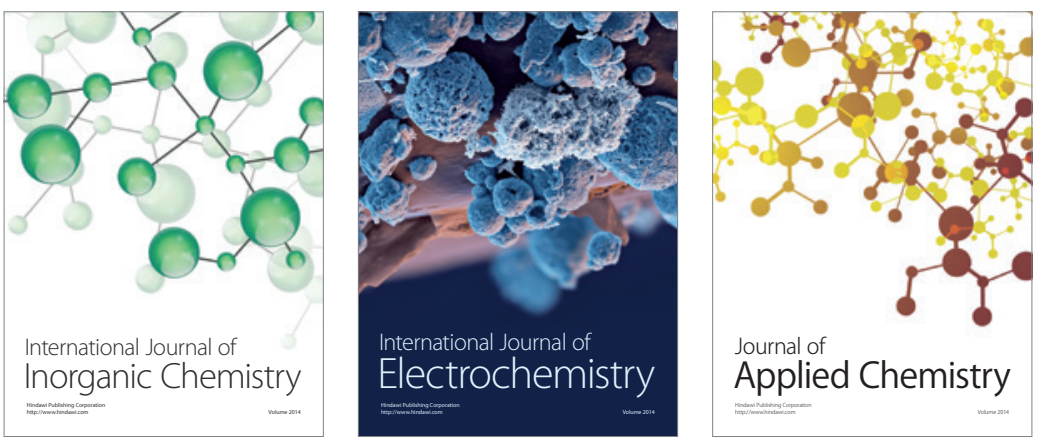

Journal of

Applied Chemistry
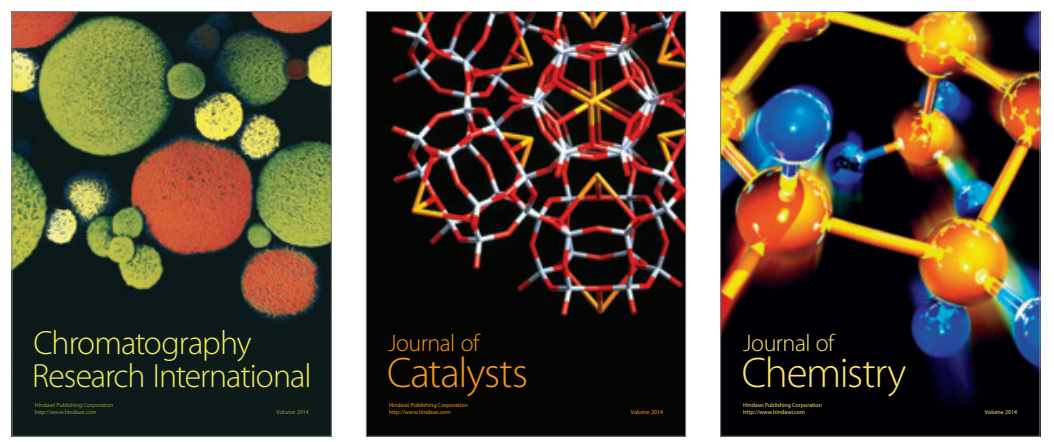
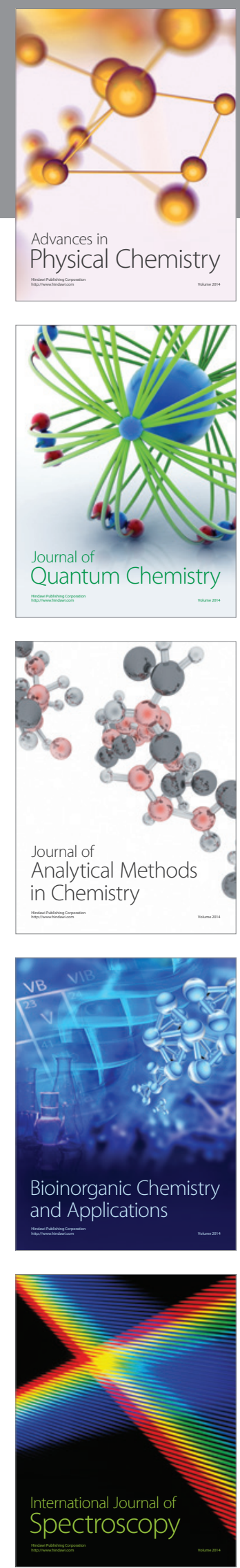